\title{
Obesity in childhood and adolescence
}

Last year it was reported that a 9-year-old boy had died at school from sleep apnoea and Pickwickian syndrome. He weighed between 105 and $120 \mathrm{~kg}$, and despite the overseeing medical doctor insisting that he be admitted for further investigations and treatment, his parents refused. He had been falling asleep in the classroom on a regular basis for 2 months before his tragic death.

Obesity rates among children and adolescents have reached epidemic proportions in both industrialised and developing countries, with an estimated 1 out of every 5 youngsters suffering from obesity at a BMI above $30 .{ }^{1}$ Childhood obesity is a strong predictor of adult obesity, and very difficult to treat once established. ${ }^{2}$ Childhood obesity also predicts an increased risk of death, primarily due to an increased likelihood of cardiorespiratory death. ${ }^{3}$ The rise in the cardiovascular death rate is explained by the increased risk factor profile from high rates of hypertension, dyslipidaemia, type 2 diabetes and sleep apnoea. ${ }^{4}$ Longitudinal studies looking at various risk factors, including carotid intima-media thickness, have indicated that adults who became obese but had a normal BMI in childhood had a more adverse risk profile. Adults who were obese as children and then normalised their BMI had a risk profile similar to patients who had never been obese during childhood. ${ }^{5}$

Given the above, active intervention in childhood obesity is likely to have a number of benefits. However, we face the difficult scientific problem that circulating levels of biological mediators of appetite which encourage weight regain after induced weight loss do not revert to the levels recorded before weight loss. ${ }^{6}$ Long-term strategies and research to counteract this change are needed to prevent obesity relapse, and so far we have failed in this area. Various other factors have contributed to our lack of success in containing childhood obesity, including living in neighbourhoods with a high level of poverty, ${ }^{7}$ sleep deprivation during childhood, ${ }^{8}$ consumption of sugary drinks, frequent ingestion of fast foods, ${ }^{9}$ and lack of physical activity. ${ }^{9}$

Less well-recognised medical conditions associated with childhood obesity include non-alcoholic fatty liver, gastro-oesophageal reflux, slipped capital femoral epiphyses, pseudo-tumour cerebri, and a high risk of certain cancers. At the onset these medical conditions may be less destructive than the stigma of obesity and the psychological trauma experienced by bullying and stigmatisation.

Morbid obesity seems virtually impossible to treat with lifestyle intervention alone. A 2-year trial of obesity treatment in primary care practice indicated that quarterly visits with brief counselling had no impact on weight loss. Enhanced weight loss counselling by lifestyle experts helped around one-third of patients to achieve a 5\% sustained weight loss over 2 years. ${ }^{10} \mathrm{~A}$ recent meta-analysis supported the view that accredited bariatric surgery in an established centre of excellence staffed by committed and adequately trained medical professionals is a good solution in adolescents. ${ }^{10}$ Patients keep their weight off in the long term and have a high rate of resolution of their co-morbidities. ${ }^{11}$ The Roux-en-Y gastric bypass involves minimally invasive laparoscopic surgery, and is the procedure most frequently performed worldwide. Mortality $(<1 \%)$ and morbidity $(\sim 4-8 \%)$ rates are low in expert hands. ${ }^{11}$

In this issue of SAMJ Ozcetin et al. appropriately highlight the importance of carotid artery stiffness and increased intima-media thickness in obese children. ${ }^{12}$

Recently Robert C Whitaker from the Department of Health in Philadelphia passed the following thought-provoking comment: 'The childhood obesity epidemic is just one symptom of our way of living. Reversing the epidemic may require that we apply a new approach to improving child and adult health in the 21 st century. One approach would be to make societal changes to enhance human well being rather than to try and prevent a particular symptom such as obesity.'

Blaming, shaming and punishing the obese will not solve the problem - it is simply shooting the messenger. If parents fail to recognise that their child is obese, they are unlikely to recognise that interventions targeting obesity are relevant to the family.

\section{T van der Merwe}

Honorary Professor and Researcher

University of Pretoria

Corresponding author: M T van der Merwe (tessavdm@iafrica.com)

\section{References}

1. Wang Y, Lobstein T. Worldwide trends in childhood overweight and obesity. Int J Pediatr Obes 2006;:111-25.

2. August GP, Caprio S, Fennoy I, et al. Prevention and treatment of pediatric obesity: an Endocrine Society clinical practice guideline based on expert opinion. J Clin Endocrinol Metab 2008;93:4576-4599.

3. Franks PW, Hanson RL, Knowler WC, Sievers ML, Bennett PH, Looker HC. Childhood obesity, other cardiovascular risk factors, and premature death. N Engl J Med 2010;362:485-493.

4. Gregg EW, Cheng YJ, Cadwell BL, et al. Secular trends in cardiovascular disease risk factors accordin to body mass index in US adults. JAMA 2005;293:1868-1874. [Erratum, JAMA 2005;294:182]

5. Juonala M, Magnussen CG, Berenson GS, et al. Childhood adiposity, adult adiposity, and cardiovascular risk factors. N Engl J Med 2011;365:1876-1885.

6. Sumithran P, Prendergast LA, Delbridge E, et al. Long-term persistence of hormonal adaptations to weight loss. N Engl J Med 2011;365:1597-1604.

Ludwig J, Sanbonmatsu L, Gennetian L, et al. Neighbourhoods, obesity, and diabetes - a randomized social experiment. N Engl J Med 2011;365:1509-1519.

Casturi L, Rao R. Association of short sleep duration and body mass index in teen adolescents. Meetin Abstracts 799A. Chest 2011;140:4 [http://dx.doi.org:10.1378/chest.1119939]

. Li F Harmer P, Cordina BJ Bosworth M Johnso Sho 137 D. Obesity and the built environment: does the density of neighborhood fast-food outlets matter? Am J Health Promot 2009:23:203-209.

Wadden TA, Volger S, Sarwer DB, et al. A two-year randomized trial of obesity treatment in primary Wadden TA, Volger S, Sarwer DB, et al. A two-ye
care practice. N Engl J Med 2011;365:1969-1979.

care practice. N Engl J Med 2011;365:1969-1979.
Treadwell JR, Sun F, Schoelles K. Systematic review and meta-analysis of bariatric surgery for pediatric Treadwell JR, Sun F, Schoelles K. Syste
obesity. Ann Surg 2008;248:763-776.

12. Ozcetin M, Celikyay Y, Celik A, et al. The importance of carotid artery stiffness and increased intimamedia thickness in obese children. S Afr Med J 2012;102(5):295-299 (this issue).

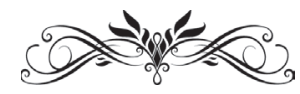

An eerie silence;

Birds, crickets, bees, trees are still -

Rain is imminent.

Haiku: Peter Folb 